Gut, 1989, 30, 1233-1235

\title{
Campylobacter pylori infection in Meckel's diverticula containing gastric mucosa
}

\author{
A MORRIS, G NICHOLSON, J ZWI, AND M VANDERWEE \\ From the Departments of Microbiology, Gastroenterology, and Pathology, Auckland Hospital and the \\ Department of Pathology, Auckland Medical School, Auckland, New Zealand
}

SUMmary A retrospective survey was undertaken of 228 resected Meckel's diverticula to determine if there was any evidence of Campylobacter pylori infection in diverticula containing gastric mucosa. Among the 65 diverticula with gastric mucosa one was heavily infected with organisms having the morphological appearances of $C$ pylori. The specimen had been removed from a six year old Samoan boy who had been admitted with small bowel obstruction. Infection and associated mucosal inflammatory infiltrate were limited to areas of gastric mucosa only. The detection of the organism at this site remote from the gastroduodenal environment suggests the organism may be transmitted by the orofaecal route.

Current evidence suggests that Campylobacter pylori can only colonise areas of gastric epithelium. The organism has been found in the stomach' and areas of gastric epithelium in the duodenum ${ }^{2-4}$ and Barrett's oesophagus." "Pambianco et al have more recently reported $C$ pylori infection at a site distal to the duodenal bulb ${ }^{7}$ where they observed large numbers of curved and S-shaped bacteria adhering to an island of gastric type epithelium in the rectum.

We have carried out a retrospective study of Meckel's diverticula to determine whether there is any evidence of $C$ pylori infection in those containing gastric mucosa.

\section{Methods}

Histology reports from three hospitals of Meckel's diverticula were examined. The presence of histological abnormalities and the presence or absence of gastric mucosa were recorded.

All diverticula with gastric mucosa or histological abnormalities had extra sections cut and stained by the half Gram method. ${ }^{*}$ These sections had their entire small intestinal and gastric epithelial surfaces examined under oil immersion by one observer

Address for correspondence: Dr A J Morris, Microbiology Registrar. Microbiology Department. Greenlane Hospital, Auckland, New Zealand.

Accepted for publication 17 January 1989. to detect organisms resembling $C$ pylori. The haematoxylin and eosin ( $\mathrm{H}$ and $\mathrm{E})$ sections of all diverticula with gastric musoca or histological abnormalities were examined by two independent observers. Particular attention was paid to the presence or absence of histological inflammation in the areas of gastric mucosa. The type of inflammation present at these sites was compared with the inflammatory cell component in the adjacent small bowel mucosa.

A paraffin embedded tissue block, seen to contain curved bacilli by light microscopy, was processed for transmission electron microscopy. The block was deparaffinised in chloroform and rehydrated through alcohol before being fixed in buffered $2.5 \%$ glutaraldehyde followed by $1 \%$ osmium tetroxide. It was dehydrated through an alcohol series and infiltrated with epoxy resin. The polymerised block was thick sectioned $(2 \mu \mathrm{m})$ to confirm the presence of bacteria, and then thin sectioned $(70-90 \mathrm{~nm})$ for examination in a Philips $410 \mathrm{LS}$ transmission electron microscope.

\section{Results}

The histology reports of 228 Meckel's diverticula were examined. One hundred and eighteen diverticula contained only normal small bowel mucosa. Forty five diverticula contained only small bowel 


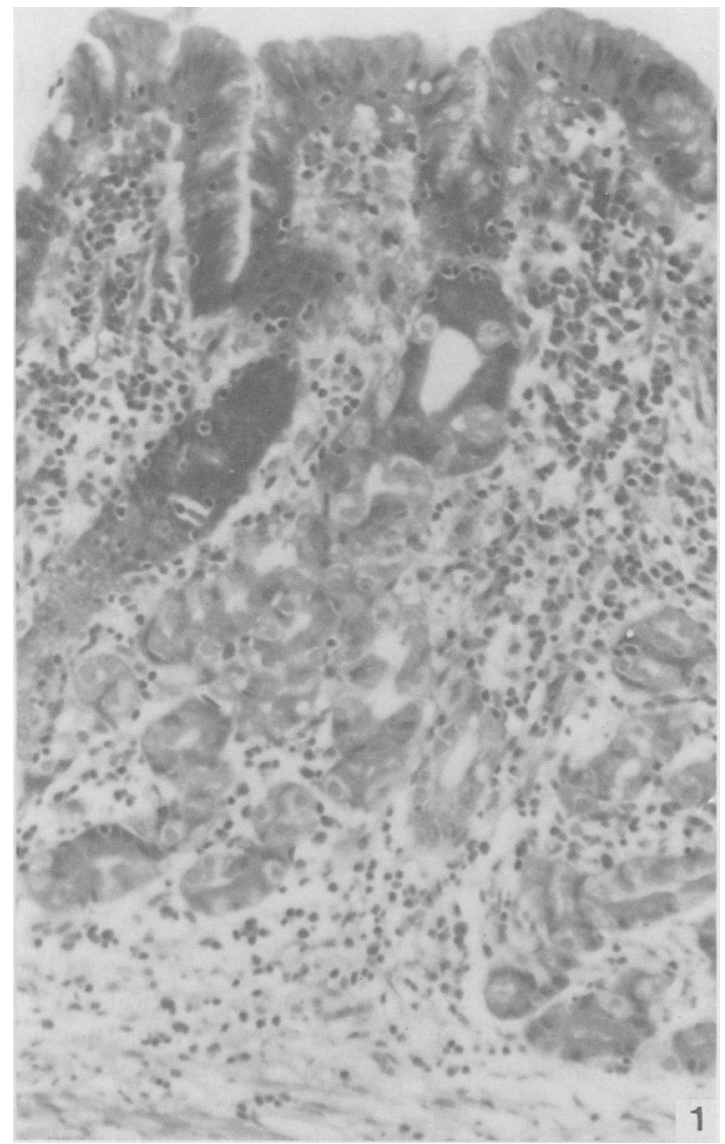

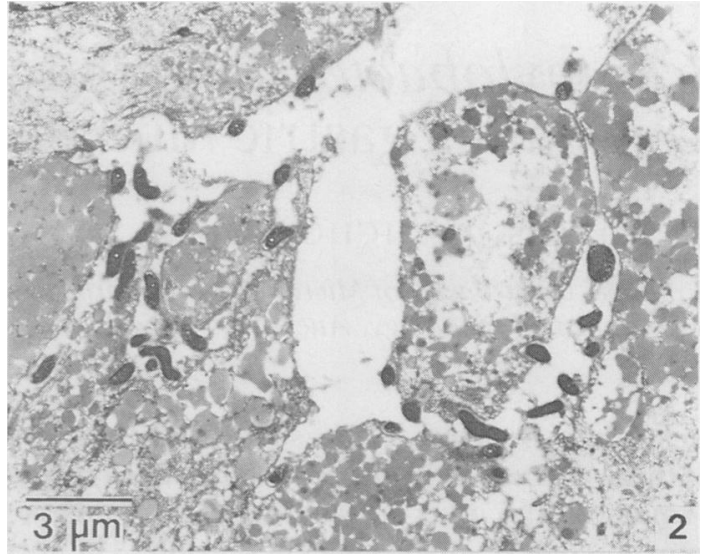

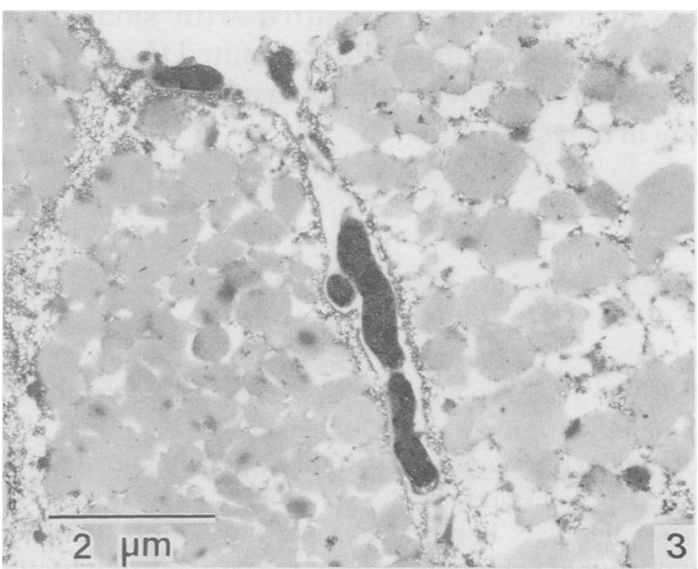

Fig. 1 Section of the wall of a Meckel's diverticulum containing gastric mucosa infected with C pylori. A mixed inflammatory cell infiltrate is present in the lamina propria. In places the epithelium is infiltrated with lymphocytes and polymorphonuclear leucocytes. (H\&E).

Fig. 2 Transmission electron micrograph of gastric epithelium in a Meckel's diverticulum. Many curved and $S$-shaped bacteria are shown in close association with the epithelial surface.

Fig. 3 Transmission electron micrograph showing curved bacilli between adjacent epithelial cells.

mucosa but had histological abnormalities recorded for example, infarction, haemorrhage, ulceration, or perforation. Sixty five diverticula contained areas of gastric mucosa and inflammation was present in the gastric mucosa of 12 of these. In eight cases, however, inflammation was also present in the adjacent small bowel mucosa. Of the four diverticula with inflammation restricted to the gastric mucosa, two had mild chronic inflammation only, and two had active chronic inflammation with polymorphonuclear leucocyte (PML) infiltration of the lamina propria and epithelium. The half Gram stained sections of one of the specimens with active chronic 'gastritis' contained organisms compatible with $C$ pylori.
No similar bacteria were observed in any other diverticula on either small bowel or gastric epithelial surfaces.

\section{Case history}

The patient, a six year old Samoan boy, was admitted in 1978 after a two day history of colicky abdominal pain, anorexia, and vomiting. On examination he was mildly dehydrated and had vague epigastric tenderness, but no guarding or rebound. Bowel sounds were high pitched, abdominal radiographs revealed small bowel obstruction.

At laparotomy the lower small bowel was found 
twisted around a fibrous band joining a Meckel's diverticulum to the anterior abdominal wall. The diverticulum itself was uninflamed. The Meckel's band was divided and the diverticulum excised.

The resection specimen consisted of a segment of small bowel communicating with a diverticulum which tapered into a fibrous band. The greater part of the diverticulum was of normal small bowel mucosa but in the narrow distal segment there was full thickness gastric mucosa of body type. The gastric epithelium contained PML's and eosinophils. A mixed inflammatory cell infiltrate of lymphocytes, plasma cells, and PML's was present in the lamina propria (Fig. 1). The infiltrate was mainly restricted to the superficial portion of mucosa but in some areas it extended between the glands. Large numbers of curved bacilli were seen in $\mathrm{H}$ and $\mathrm{E}$, half Gram, and Warthin-Starry silver stained sections. Electron microscopy revealed S-shaped bacilli in close association with the gastric epithelium and between adjacent gastric epithelial cells (Figs 2, 3). Occasional structures resembling sheathed flagella were observed. No organisms were seen on the adjacent small bowel mucosa.

\section{Discussion}

We have found evidence of $C$ pylori infection in a Meckel's diverticulum containing gastric mucosa. The diverticulum was removed after the patient's presentation with small bowel obstruction and it is unlikely that $C$ pylori infection was responsible for any of the patient's symptoms. Although the organism was not cultured from this site, the size, shape, and ultrastructure morphology of the organism as well as its presence as a single bacterial population and association with superficial active chronic 'gastritis' were all compatible with its being $C$ pylori. The organism has in this and other reports ${ }^{1-h}$ only been identified on gastric epithelium suggesting infection may be limited to such sites.

No organisms similar to $C$ pylori were observed in any of the sections from the other 109 diverticula examined. The length of epithelium examined in each case was orders of magnitude greater than the area contained in gastric biopsies where histological methods detect $C$ pylori in $93 \%$ of infected patients." It is unlikely therefore that $C$ pylori was missed in these diverticula.

Finding $C$ pylori in a Meckel's diverticulum some distance from the usual site of infection in the stomach suggests that the organism is able to survive the environment of the small bowel. Panbianco et al have recently reported finding curved bacilli morphologically similar to $C$ pylori on an island of ectopic gastric mucosa in the rectum. ${ }^{7}$ These findings show that $C$ pylori may survive to reach the distal bowel and therefore that the orofaecal route may be a mode of transmission for this organism.

Although attempts have been made to culture C pylori from stool specimens," we are unaware of any report recording its successful isolation. Nevertheless there is some support for orofaecal transmission. ${ }^{5}$ Higher rates of $C$ pylori antibody are found in institutionalised patients and antibodies are found at younger ages than in age matched blood donors." Families of children with proven $C$ pylori infection have a higher prevalence of $C$ pylori antibodies than in age matched controls. Although other reasons may explain the serological findings - for example, common exogenous sources of infection, they are at least consistent with the possibility of orofaecal spread.

The authors wish to thank Professor John Arthur, and Drs David Becroft and Renzi Palmer for access to the surgical material. Mr Murray Silverstone and Kathy Patton provided excellent technical assistance.

\section{References}

1 Marshall B, Warren J. Unidentified curved bacilli in the stomach of patients with gastritis and peptic ulceration. Lancet 1984; i: 1311-5.

2 Steer H. Surface morphology of the gastroduodenal mucosa in duodenal ulceration. Gut 1984; 25: 1203-10.

3 Johnston B, Reed P, Ali M. Campylobacter like organisms in duodenal and antral endoscopic biopsies: relationship to inflammation. Gut 1986; 27: 1132-7.

4 Wyatt J, Rathbone B. Dixon M. Heatley R. Campylobacter pyloridis and acid induced gastric metaplasia in the pathogenesis of duodenitis. J Clin Pathol 1987; 40: 841-8.

5 Mitchell H, Bohane T, Berkowicz J, Hazell S, Lee A. Antibody to Campylobacter pylori in families of index children with gastrointestinal illness due to $C$ pylori. Lancet 1987; ii: 681-2.

6 Paull G, Yardley J. Gastric and oesophageal Campylobacter pylori in patients with Barrett's ocsophagus. Gastroenterology 1988; 95: 216-8.

7 Pambianco D, Dye K. Marshall B, et al. Gastritis in the rectum: Campylobacter-like organisms in heterotrophic inflamed gastric mucosa [Abstract]. Gastroenterology 1988; 94: A340.

8 Trowell J, Yoong. Sauk K. Grant P. Bell S. Simple halfGram stain for showing presence of Campylobacter pyloridis in sections. J Clin Pathol 1987; 40: 7()2.

9 Morris A, Ali R, Brown P, Lane M, Patton K. Campylobacter pylori infection in biopsy specimens of the gastric antrum: laboratory diagnosis and estimation of the sampling error. J Clin Pathol 1989; 42: 727-32.

10 Marshall B, McGechie D. Rogers P, Glancy R. Pyloric campylobacter infection and gastroduodenal disease. Med J Aust 1985; 142: 439-44.

11 Berkowicz J, Lee A. Person-to-person transmission of Campylobacter pylori. Lancet 1987; ii: 680-1. 